\title{
Dreams and a New Building
}

$\mathrm{D}^{\circ}$ YOU SOMETIMES SIT AND WONDER what you would do if you were to have a new building and could plan it as you wished? Do you drift quietly off to sleep full of ideas about how wonderful it would be if you could only get out of that old firetrap you work in and could see yourself in a bright and shiny, new, efficient building? Do you find you wake in the morning having solved in the dark recesses of a night's sleep all the problems of this building which you have created between 4 and 5 A.M.?

Well, perhaps you should have a new dream. Do you know what problems need solving; and do you know that a new building doesn't solve your problems? It only gives you an opportunity to think about the ones you have, and offers many more to wonder about.

What are the problems librarians think about, whether they are in an old library and must make do with what they have, or are about to embark on the great adventure to find new ways of giving excellent library service to students - or to other clientele?

\section{General Problems}

It is not the concern of this paper to outline the philosophical implications of library service. It may be assumed that by the time a new building is thought about that there is general campus enthusiasm for it and that sincere consideration has been given to the basic reasons for providing good service.

As you think about this new building, is it clear what your role in the planning process is going to be? Are you going to

\footnotetext{
Dr. Smith is director of libraries, Louisiana State University.
}

be on the advisory committee which works toward putting a program down on paper and then submits it to an architect? Can you show that your building will be better if you are part of the planning process, even if you feel that you do not know all you wish to about library buildings?

Who will decide whether you wish an outside consultant? You will undoubtedly feel a little lost as you begin planning and will want someone to talk to about your ideas. Is a consultant-one who has had rather extensive experience - of help? He might give you ideas with which you will disagree and therefore you will have to work hard to defend your own-or he will convince you. Can he serve to test faculty and student reaction to various ideas current on your campus? Almost always a consultant is a busy person, interested in being helpful but in need of specific directions as to what is wanted of him. Do you want him for a day or a month? Do you want him to do plans or only assist in formulating a library program which can later be developed into plans? Is his relationship clear to you, to your administration, and to the architect? Do you know exactly how you can handle the finances? Consultants should be adequately paid. Will you want your consultant only in the early stages of a building or will you want him to see the building to completion?

If one consultant serves your needs for the basic building, what will you do when it comes to colors, furniture and equipment of various kinds?

With your role and that of a consultant clear, are you ready to start on the building? Are you to have a divisional arrangement? Much has been written on 
the subject, and you can find examples to study so that you know how it is thought to work out in other institutions. But do you know why it should or should not be used in yours? Perhaps it seems good sense from the library administration standpoint, but is that a good enough reason? Is there something about the way your institution is organized which makes it logical to have divisions in the library? You may well come out in your thinking with the need for, let's say, a humanities division, a science division and a social science division. Can you tell from the way students take courses, or from the way the literature appears, that such a scheme has real merit for you? Or would it be more sensible to have an undergraduate library, a general library, and a research library all separate within your building? Or possibly a combination?

Do you know whether you are going to urge very strongly that the new library be a centralized library, or are you going to want to maintain departmental collections in various places on the campus? If there are departmental collections, do you know whether you can afford to staff them, and what size they should be before staffing is necessary, or how many volumes make a working collection which a departmental secretary can successfully look after? If some departmental collections are to be expected do you have a pretty good idea how much duplication is going to be advisable, or financially possible?

What are you going to be able to say about the advantages of a closed or an open stack-or are you going to have a stack area at all? Some recent buildings are arranged on a divisional plan, but in connection with these divisions there is a central stack core. If you have completely open stacks, are you going to have enough money to hire students to put books back in order-and keep them that way?

And from the beginning you are going to be faced with financial problems, not only connected with the building itself but with all aspects of what the new building makes it possible for you to do. So far as we know, every new building increases the demands made on the library and enlarges its sphere of operation. Will you need new staff and new services? Can you spend the money needed to make this new building work for you better than the old one? Can you improve your routines and equipment - which you would always liked to have done anyway-so that you have an efficient but personable operation where people can get what they want when they want it with few obstructions put in their way and every effort made to have things as simple and straightforward as possible? As your services increase and the requests for longer library hours are heard, can you staff the building easily with only a few people at a time?

\section{Public Services}

If it is assumed that you will have a divisional arrangement-and the assumption is made not necessarily because this is the best way of doing things but just because it is one way, and you have to start somewhere-what kinds of services are you to provide in the divisions? Will you want to have a central reference department, perhaps similar to what you now have, or would it be better to have the reference work carried on by suject specialists in the divisions? If you do not have a central reference department, you may need some information service quickly available near the entrance, you may want to give some assistance in the use of the card catalog, and you may want to have your bibliographical section conveniently near the cataloging or technical services offices. Can you do all this, and, if not, which need has priority? And what do you do about the requirements of departments or schools which cross divisional lines? And where do you put reserve books?

It may be possible to work out, without too much stress and strain, the details of 
giving good reference service wherever it is needed in a building. An equally important question is the location of circulation points. You will also want to consider where book-return boxes from the outside can be located.

If you are going to do at least some reference work in the divisions, you may then ask whether each division will also circulate its own material and keep its records, or whether there should be a central circulation area for all service.

Once the circulation desk or desks have been decided upon, the charging system must be selected. What is desired is a method which does not take time for preparation in technical services, does not delay the borrower by much written work, eases the load at the circulation desk when books go out, and is simple to use in discharging books so that those which have been returned may go at once to the shelves. In addition you may want to know who has what book and when it is to be returned, and you may want to take reserves on books in circulation. Does such a system exist?

It will be necessary, however, to determine whether the records from a decentralized circulation process should be brought together in one place or whether those from a centralized system should be duplicated in the divisions. An arbitrary decision may be the only way, but there will be many requests-probably most frequently from the staff-to see that duplicate records are available. A good deal of thought must be given to the problem of duplication wherever it appears, for some of these requests may be expressions only of a familiarity with how things have been rather than of a need under a new method of operation.

\section{Arrangement Within Divisions}

The assumption has been made that a divisional arrangement would be followed in your new library - and although this may not be necessarily the right assumption, it is a workable one, and, if it is made, certain problems develop which must be solved. What, for instance, should be the arrangement of the material within the divisions? Frequently it happens that there have been departmental collections or branch libraries, and a new building may encourage some or all of these outside collections to be housed in the new building. When they are brought together, should they be housed as separate units as they were when they were in different places on the campus? Many departments may like this for they will feel the same close ties to their collection-and to their librarian-that they have had. Is this the best arrangement that can be devised, or would it be more satisfactory if each division was known to contain certain parts of the classification scheme? If there are existing branch libraries, when a move to a larger building is made it may be discovered that each of them has books from all parts of the classification scheme. Should these somehow be maintained within the general subject area where most of the books from the branch are shelved, or should they be put where they fall in the classification schedule, with a concerted effort made to inform people what is taking place? If various classification numbers are to be represented in each division it will be evident that the cards in the catalog will have to bear location symbols. The decision as to whether this is advisable or economically wise will have to be made fairly early in the planning process.

It will soon be evident even with a divisional arrangement that not all materials fall within the divisional framework. What of recreational reading, for example? Do you believe in browsing rooms and do you want ta make some "general" reading available?

So far the emphasis has been on book materials, but other groups of material are crying for answers to problems which they raise. What should be done with periodicals and documents? Is it better to establish a periodical room where all 
serials are shelved-and possibly arranged alphabetically by title-or is it much more satisfactory to have that kind of material classified and arranged along with book material in the same subject? Perhaps these questions can only be answered from a historical standpoint. If a library has classified its periodicals there may be no reason for changing to an alphabetical arrangement; if on the other hand the arrangement has already been alphabetical there is doubt as to whether it is worth while to classify. Only when there has been a mixture of the two, and perhaps inadequate records in addition, would it be advisable to get all of them in one arrangement or another. Actually, of course, there is another possibility: to arrange serials of a given subject alphabetically by title and house them in a separate part of a division so that periodicals are near their subjects but still separate and alphabetical. If serials from all the library's divisions are to be separate and alphabetically arranged, then space must be found for them apart from the divisional arrangement.

With documents, the situation is both different and similar. Are documentsand here is meant not only United States government publications, but United Nations documents, publications of foreign governments, and documents from our own states-to be classified in the library's classification and shelved along with all other material? We must consider their number, and the means which have been provided for getting at them. There is an argument for relying on printed indexes and on prepared classification schemes which must be carefully weighed as the decision is made to shelve them separately or with other subject material. Is the Superintendent of Documents classification to be used, or will some material be maintained in the library's general classification scheme? How much of this material should exist?

Is the map collection large enough to have a separate room, or can it be ab- sorbed by a division? Are horizontal or vertical cases to be preferred for the maps, and how thick should the drawers be?

\section{Technical Processes}

Some of the previous matters have been called "public," but it is clear that they have technical aspects also; and in this section, though it is labeled "technical" there will be items which will have public connections. It is hard to separate clearly the two and to identify them distinctly. There is general agreement that the basic aim is public service and that the important things which go into the technical work are aimed at improving and expanding that public service and are not-and should not become-ends in themselves.

A vital decision must be made early in planning for the new building: Are you going to maintain your present classification system or is this the time to do something drastic about its shortcomings? Much of the final decision may be made on financial grounds, but the advantages of some new classification may be more theoretical than real. It is fair to say that no classification scheme has or will ever be devised that is entirely satisfactory to all people who use it. It may therefore be not only expedient to save what you can by not changing schemes but it may be even wiser to use to the fullest extent possible the advice you pay for on Library of Congress cards, and go more and more in the direction of thinking of the classification system you use as a reasonable guide to your collections and not as the perfect scheme to guarantee that all your material on a subject will be shelved together.

What about the technical departments themselves? Are you going to have all your departments combined under one head, or at least located in one area of the building? Where is that area to be? Traditionally it has been thought necessary to have it adjacent to the public card cat- 
alog and preferably on the first floor of the building. It would not be hard to show examples of where it has been placed elsewhere without dire results. It is true that the acquisitions and cataloging staffs use the card catalog frequently and need easy access to whatever they are using. But it is important to be sure that some vital public service is not being slighted to make possible the juxtaposition of the card catalog, the bibliographies, and the technical processes department. If all can be accomplished together, everyone concerned will be contented. If it cannot be, it is possible at least to consider placing public needs above staff needs, particularly if other staff needs can be met by some other combinations.

Has it been decided that all cataloging will be done by the cataloging staff alone, or is some arrangement being considered whereby the advice and assistance of the reference staff can be used? Have we become too departmentalized and should some combination of library duties be considered?

What kind of catalog is going to be needed: a union catalog for all the building (and should this be divided); additional catalogs in each division (and need these be dictionary catalogs or would an author one suffice)? Should the catalog contain all serials entries? This serials problem is a very tough one because the bulk of the material is so great, the need for accurate records so important, and the complexities of the material so enormous that one's first reaction is to have as many records as possible because it is so difficult to tell what will be needed. Does the library need complete records of its serial holdings in more than one place? If so, should these records be in the catalog and in the shelf list? Should there be one complete record of past and present serials with no record in the public catalog? If so, how can this one serials record be served? Does the existence of open or closed stacks have an influence on this decision? Can the divisions get quick and accurate information by telephone to a central file, or is duplication essential?

The responsibility of the binding department in looking after all materials in the divisions is of direct concern. Shall it be the binding department's job to pick up and send to the bindery all divisional material, or will the divisional personnel have that responsibility? Will the binding department be so closely related geographically and administratively that it in effect becomes an integral part of technical processes and assumes the task of pasting and plating and marking?

How much book-marking is done in the library? We mark the entire call number, of course, on the back of the volume. Has it yet been proven that we need an author or Cutter number as well as a classification number? Or do we keep it as part of the cataloging routine only because it has been so long a part of it? We need to question its place in academic libraries, particularly since its primary function is one of identification and since public libraries have been identifying their books for years without it. And why have we not made it possible to read classification numbers by marking in really big numbers and letters?

Finally, as we consider technical process problems, what about a receiving and shipping area? Has it been located correctly on the lowest level of the building, so that material comes directly to it on receipt and is then directed away from it in one general direction without duplication of movement; and does everything going out of the building funnel through it from all parts of the building? Is it big enough? Is it closely related to a supply room? Who handles supplies so that they are well inventoried, correctly ordered, and available on short order whenever they are needed? Is the storage area big enough?

\section{Details-Miscellaneous But Not to Be Forgotten}

There are many things about a new 
building that do not fit conveniently into any category but which need to be considered. Though apparently unrelated either to the more general outlines of the building or to each other they are significant and should be mentioned one by one.

Module size.-Currently it is fashionable to build according to the modular principle of repeated units the same size in order to gain flexibility. But what size should the module be? A quick review of recent buildings reveals such a wide variety of sizes that it is bewildering to know Theoretically a library will want a modhow these were arrived at-and why. ule of a size which will accommodate standard items: shelving, furniture, floor tiles, acoustic plaster, lighting fixtures, air ducts and lighting outlets. But how many module sizes do this? A little study with a slide rule should reveal the best possible size — or sizes_-but this has as yet not been done with definitiveness. Someone might devote himself to this question so that we will know what we should be aiming at.

Ceiling heights.-Take a look at some recently constructed buildings to see whether you are satisfied with the distance between floor and ceiling in the various rooms. Possibly a uniform floor height throughout the building is advisable; perhaps you will want some variations between adjoining rooms. If so, remember that this must be compensated for in some way when considering the building as a whole. You may be surprised to see that ceiling heights only slightly over 8 feet are not impossible even in a large area. But heights up to 9 feet may be more acceptable, and more spacious looking. Do you know whether the same ceiling height is possible in a basement room with no windows as in a main or upper floor room with more extensive views of the outside world? Sometimes ceiling heights are influenced by the type of lighting fixtures. A fixture flush with the ceiling may make it possible to have a slightly lower ceiling because less space is taken by the fixture itself. Is this a fairly good rule to consider: a ceiling high enough so that one does not feel cramped and low enough so that not too much space is wasted?

Mezzanines.-The question of floor heights suggests mezzanines which can serve as a means of heightening a ceiling in parts of a room while making interesting use of other space. Some of the handsome new buildings have made effective use of mezzanines and have enhanced the attractiveness of the interiors. Several questions should be raised about them, however: Do they make as good use of space as would be the case if they were complete floors; do they confuse the reader; do they cause separation of parts of the collection in such a way that a logical pattern of shelving is difficult; do they cost more or less than a different construction; do they increase the amount of space available without cutting it up with an elaborate array of concrete or steel supports? Do we know how thick a mezzanine floor should be and how this thickness is influenced by lighting fixtures now or in the future; or do we know what proportion of a floor should be in mezzanine before one is advisable?

Air conditioning.-Do you know accurately what air conditioning would cost? Can you make a decision whether to have it in a building of the size needed, or must a smaller building be erected if air conditioning is to be included? Are you sure that a smaller air-conditioned building with possibility for later expansion would not serve better in the long run?

Flooring.-These days there are a number of choices in materials for library floors. Do you want yours quiet and expensive, medium-priced and shiny, relatively inexpensive and rather hard? Apparently the day of the wooden floor has passed into some never-never landwhich may be just as well, for it was somewhat difficult to maintain and was somewhat hard, but given a little care it certainly did last. Now, except for lobbies 
and stairways where terrazzo is often used, we seem to have a choice of various tiles. They vary tremendously in price and durability, and they come in a number of patterns. So far there does not appear to be a flooring as quiet as foam rubber or carpet, as durable as plastic tiles are expected to be, as handsome as wood, or within a price range we can affordand one is needed, not only in libraries, but in public buildings of all kinds.

Variations in the costs of flooring may come as a surprise. One type of flooring tile is four times as expensive as the cheapest, and even it has its very serious drawbacks.

Shelving.-Today there are several types of shelving available, some slotted, some bracket type. Is each interchangeable with newspaper or study shelves, and is each easily installed? Is some provision made for pamphlets and recordings by the use of shelves which will accommodate upright supports at intervals?

Communication.-How are you going to get information from one place to another, and how are you going to move materials? Will dial telephones serve all the needs you have, particularly if some of the instruments are fitted with several lines, or do you need an intercom system? And how are you going to get books back on the shelves - or off them if you have a closed stack arrangement? Perhaps book trucks will move materials around fast enough, but you may have to consider mechanical conveyor belts, particularly if books circulate rapidly and you do not have enough student assistants or book trucks to get books back to the shelves before a crisis has developed at the circulation desk. Be sure your pneumatic tubes are big enough to hold a reasonably large piece of paper or card stock, and be sure you have estimated carefully the load your tube system will be called on to carry. It is as easy to find libraries which have tubes they no longer use as it is to find others with tubes too small in diame- ter going to too few places and taking too long to carry out their job.

Elevators.-Related to the transmission of messages and books is the problem of making it easy for your patrons to get around the building. Do you know how many people you will have in your library? Can you be sure that the one elevator which may fit your budget is anywhere near adequate? Is it possible to make a space for additional ones even if the actual machinery is not installed at the beginning? Do escalators have a potential use, even though none has yet been installed in a library?

Lighting.-We have come a long way from the days when a single unshaded light was considered adequate, for now there are in some office buildings continuous and totally luminous ceilings. Libraries may not yet have arrived at this point but there is much we can do to fit in between the extremes. How can we make plans so that the lighting once installed is not so rigid that it determines the use to which parts of the building are put?

If fluorescent lighting is chosen for a building, we must ask our lighting consultant whether a line of single tubes is satisfactory or whether a double line must be considered because it gives more light and reduces flicker, which can be irritating, if perhaps not very important.

An unsolved lighting question is how much is needed. It is sometimes said that the amount is not as important as the lack of glare or the degree of contrast. These must all be taken into consideration, for lighting should be adequate, uniform and universal. Some say lighting of 18-25 foot candles is fine; others prefer nearer 50 . Probably whatever you use will be more than in your present building, but will it be enough?

A general light switch by the front door for building light control has been recommended to eliminate the long time need to shut out all the lights. We should ask the lighting engineers to agree on one point: Should fluorescent lights be turned 
off after each use, or is it less expensive to leave them on once they have been turned on?

Furniture and equipment.-Is the furniture going to be durable, colorful, in the right price range? It almost appears that all libraries built recently look alike, because the furniture is about the same. Can we use furniture from other sources to advantage? Who is to help in this selection? Perhaps we cannot ever satisfactorily solve our problems of equipment and furniture, but let us be alert to the possibilities of delay in manufacturing so that our orders are sent in time to guarantee delivery.

Exhibits.-New buildings provide an opportunity-and a temptation-for exhibit cases. Can these be filled with good exhibits, frequently changed by an overworked staff, or should the number of cases be held to a minimum? Where do you prepare for exhibits, and store exhibit materials?

Photography, radio and television.You can be sure that if you have had photographic facilities in your old building you will want some in the new one. But how much? Do you want to be able to microfilm newspapers, and then make prints from the negatives? Will you need to make slides or filmstrips? If you do not need them now, can you be sure that you will not need them in the future? What about the quick copying devices for letters or other material which you need in multiple copies? What of catalog cardsshould they be reproduced on a typewriter, on a fast-running copying machine which uses stencils, or by some other means?

How do you feel about a collection of recordings, and how are records to be used? Some may be charged out, some may be used in classrooms, some may only be available to users of the library building. Are you to have listening rooms, and how many? Are you to have tables with headphones?

Are you having the library wired for sound so that announcements can be made throughout the building, or music played in more places than the listening rooms? What about television? Is closedcircuit telecasting active enough so that you will want to be prepared for it? Or will you want only to provide for receiving commercial television?

While you think of these subjects you will want to review the whole question of audio-visual materials. Is your institution going to be more and more interested in such items, and is the library a good (or the best) place to administer them?

Windows.-Has it been decided what function windows really perform? Are they needed for ventilation, or to prevent claustrophobia, or for the appearance of the building? If the building is to be air conditioned, it is often more expensive to have windows than to do without them. Is it worth something quite specific to have windows so that an already existing architectural pattern on a campus may be maintained, or so that the so-called psychological advantages of being able to see outside can be realized?

Conveniences and special needs.What kind of lounge facilities are to be provided? Will the staff need a separate area for their lunches or can this be combined with a general lounge where faculty and staff can meet regularly and where special functions may be held? Do you need a kitchen?

How many washrooms are to be provided, and is it too much to want facilities on each floor? What about the new plumbing for the women's lounges?

Where is smoking to be permitted? What influence does air conditioning have on this decision?

Will study rooms be provided for your faculty and for graduate students? What proportion of your total seating capacity should be set aside for reserved use of this kind? Are these rooms to be assigned for a specific length of time-and what is that time? What of lockers in various places in the building? Should these be 
operated by keys, or do coin lockers serve as well, particularly if the mechanism is of the kind in which a coin operates the lock but is returned to the user?

Where is typing to be permitted? Can furniture and shelves be arranged and areas made sound-absorbent enough so that typing can be almost universal? Are separate rooms much more satisfactory?

Signs.-Have you faced the question of how you will direct people around your new building? Are signs going to be relied upon, and how do you make them so that they are prominent, attractive, inexpensive, and quickly produced?

Moving.-Do not forget that provision must be made for moving into your new building. One can hope that this will not come from your building budget, but it must come from somewhere-and it may be a considerable item. Can you plan ahead enough so that you do not get caught short on this important operation?

Coordination.-Your building will not get built by itself. You need constant consultation, advice and encouragement. Can a way be devised so that during its construction you have regular meetings with your architects, contractors and subcontractors? They will need your help and you will need their knowledge and detailed information.

A multitude of other questions must be asked and answered before your building is complete; but this should serve as a starter on the way to get some of them answered.

P.S. We are getting a new buildingor had you guessed? Our answers to some of these pertinent questions may not prove to be the same as those for other institutions, but we are hopeful that they are suggestive.

\section{New Union List of Serials in Prospect}

The Rockefeller Foundation has made a grant of $\$ 6,000$ to the Library of Congress to permit the Joint Committee on the Union List of Serials to develop a new union list program. The aim is a permanent and self-sustaining union list of serials.

Wyllis E. Wright, who is librarian of Williams College and who for fifteen years was chairman of the Joint Committee, will spend the next three months, largely at the Library of Congress, carrying out the basic investigations. The new program is necessary because editing and publishing costs, plus the expense libraries must face in periodically checking their holdings, make further editions of the Union List of Serials along traditional lines almost prohibitively expensive. Also the Joint Committee is aware that other union list activities deserve attention, especially in those areas in which some publication has already taken place (foreign government publications, international congresses, American newspapers).

The general goal is to establish at the Library of Congress a union catalog of serials. From this catalog union lists of various kinds-alphabetical, subject, country or region, etc.-could be produced systematically. The work would dovetail with New Serial Titles, whose first five-year cumulation, published last year, represents a stage in the union list program. At the same time the Joint Committee is exploring ways of keeping the existing Union List of Serials in print in some form, preferably with some changes and additions. 